ĖESTI NSV TEADUSTE AḰADEEMIA TOIMÉTISÉD. KEÉMİA

ИЗВЕСТИЯ АКАДЕМИИ НАУК ЭСТОНСКОИ ССР. ХИМИЯ

PROCEEDINGS OF THE ACADEMY OF SCIENCES OF THE ESTONIAN SSR. CHEMISTRY

$1985,34,2$

удК 677.494 .675

Л. КУТЬННА, В. ПОЛУДЕННАЯ, В. РОЖАНЧУК, Айли КОГЕРМАН, О. КИРРЕТ

\title{
ОЦЕНКА ВЛИЯНИЯ МОДИФИЦИРУЮЩИХ ДОБАВОК НА ТЕРМИЧЕСКУЮ УСТОИЧИВОСТЬ ПОЛЫХ ВОЛОКОН ИЗ ПОЛИКАПРОАМИДА МЕТОДОМ ПИРОЛИЗНОЙ ГАЗОВОЙ ХРОМАТОГРАФИИ
}

L. KUTJINA, V. POLUDJONNAJA, V. ROZANTSUK, Aili KOGERMAN, O. KIRRET, MODIFITSEERIVATE LISANDITE MOJU UURIMINE POLOKAPROAMIIDIST MEMBRAANKIUDUDE TERMILISELE STABIILSUSELE POROLOOSGAASIKROMATOGRAAFIAMEETODIL

L. KUTYINA, V. POLUDYONNAYA, V. ROZHANCHUK, Aili KOGERMAN, O. KIRRET. PYROLYSIS GAS CHROMATOGRAPHIC ANALYSIS OF THE EFFECT OF MODIFYING ADDITIVES ON THERMAL STABILITY OF POLYCAPROAMIDE MEMBRANE FIBRES

Разработка технологии получения полимерных мембран в форме полых волокон является в настоящее время одним из перспективных направлений в химии полимеров. Испытания на предприятиях азотной промышленности показали, что полые волокна из поликапроамида (ПКА) отвечают основным требованиям, предъявляемым к полупроницаемым мембранам для разделения газов. Однако для улучшения газоразделительных свойств ПКА, при сохранении таких требований к полимерным мембранам, как химическая стойкость и неизменность их эксплуатационных характеристик (в течение 2-х лет), представлялось целесообразным провести исследования по направленному изменению свойств ПКА. В качестве модификаторов были использованы соединения различной химической природы (сшивающие агенты: терефталевая кислота (ТФК) и кремнийорганические соединения - CM-5 и силазан Т; наполнители: сажа ДГ-100; пластификаторы ПМ-54 и ДЭБСИПА), которые вводили в расплав полимера путем смешения в экструдере. Из полученных модифицированных образцов ПКА на шнековой прядильной машине формовали волокна и определяли коэффициент проницаемости $\mathrm{He}, \mathrm{N}_{2}, \mathrm{CO}_{2}$ и $\mathrm{NH}_{3}$ объемометрическим методом ['].

Установлено, что из серии исследованных модификаторов наиболее эффективными добавками являются сажа ДГ-100 и циклические силазаны $\left[{ }^{2}\right]$. По коэффициенту газопроницаемости полые волокна из ПКА с этими добавками превосходят остальные на 1,5-2 порядка.

В целях определения устойчивости модифицированного полимера к термическому воздействию во времени изучали состав продуктов термодеструкции ПКА методом пиролизной газовой хроматографии (ПГХ). Пиролиз образцов модифицированного ПКА проводили при температуре $500{ }^{\circ} \mathrm{C}$. Условия хроматографии: колонка длиной 3 м и диаметром 6 мм, наполнитель - тепарон, скорость газа-носителя (гелия) - 70 мл/мин, программа температуры колонки - от 30 до $120^{\circ}$ оо скоростью $3^{\circ}$ мин.

Судя по результатам ПГХ, выходы продуктов при пиролизе модифицированных образцов ПКА и исходного ПКА почти одинаковы, т. е. влияние добавок на выходы продуктов пиролиза весьма незначи- 
Относительный выход продуктов термодеструкции модифицированного ПКА при температуре $500{ }^{\circ} \mathrm{C}$, \% от выхода при пиролизе исходного ПКА

\begin{tabular}{|c|c|c|c|c|c|c|c|}
\hline Состав образцов & $\mathrm{CO}$ & $\mathrm{CO}_{2}$ & $\mathrm{H}_{2} \mathrm{O}$ & $\mathrm{NH}_{3}$ & $\mathrm{CH}_{4}$ & $\mathrm{CO}_{2} / \mathrm{H}_{2} \mathrm{O}$ & $\mathrm{CO} / \mathrm{H}_{2} \mathrm{O}$ \\
\hline 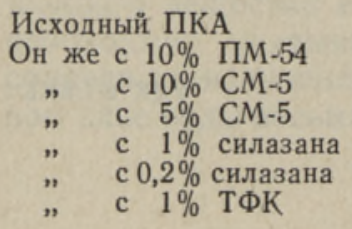 & $\begin{array}{l} \\
\quad 0 \\
+8,8 \\
+14,9 \\
+25 \\
+11,4 \\
+15,7 \\
+8,1\end{array}$ & $\begin{array}{l}\quad 0 \\
+23,5 \\
-6,6 \\
+10,6 \\
+12,2 \\
+170 \\
+24\end{array}$ & $\begin{array}{l} \\
\quad 0 \\
+31 \\
+74,5 \\
+89 \\
+39,7 \\
-7 \\
-58\end{array}$ & $\begin{array}{l}\quad 0 \\
\pm 0 \\
+15 \\
+12,6 \\
+12,6 \\
+19 \\
+20\end{array}$ & $\begin{array}{l}\quad 0 \\
\pm 0 \\
+11,4 \\
+30 \\
+15 \\
+12,9 \\
+14,3\end{array}$ & $\begin{array}{l}0,58 \\
1,300 \\
0,31 \\
0,33 \\
0,47 \\
0,88 \\
1,75\end{array}$ & $\begin{array}{l}1,30 \\
2,43 \\
0,86 \\
0,85 \\
1,04 \\
1,63 \\
3,14\end{array}$ \\
\hline
\end{tabular}

Таблица 2

Данные исследования термостойкости мембранных поликапроамидных волокон методом ступенчатой пиролизной газовой хроматографии

\begin{tabular}{|c|c|c|c|}
\hline \multirow[b]{2}{*}{ Образец } & \multicolumn{2}{|c|}{ Температура, ${ }^{\circ} \mathrm{C}$} & \multirow{2}{*}{$\begin{array}{c}\text { Относитель- } \\
\text { ный выход } \\
\varepsilon \text {-капро- } \\
\text { лактама, } \\
\%^{*}\end{array}$} \\
\hline & $\begin{array}{c}\text { начала } \\
\text { выделения } \\
\text { \&-капро- } \\
\text { лактама } \\
\end{array}$ & \begin{tabular}{|c|} 
максималь- \\
ного выхода \\
$\varepsilon$-капро- \\
лактама
\end{tabular} & \\
\hline $\begin{array}{l}\text { Исходный ПКА } \\
\text { Выдержанный }\end{array}$ & 390 & 440 & 0 \\
\hline $\begin{array}{cl}9 \text { мeс. } & \text { в } \mathrm{CO}_{2} \\
" & \text { в } \mathrm{NH}_{3} \\
" & \text { в } \mathrm{Ar} \\
" & \text { в } \mathrm{H}_{2}\end{array}$ & $\begin{array}{l}390 \\
400 \\
390 \\
395\end{array}$ & $\begin{array}{l}460 \\
480 \\
450 \\
445\end{array}$ & $\begin{array}{r}+12 \\
+11 \\
0 \\
-4\end{array}$ \\
\hline 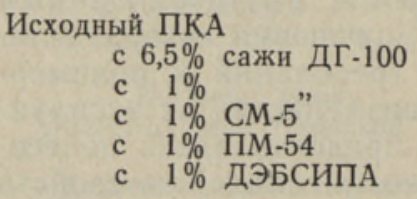 & $\begin{array}{l}400 \\
380 \\
385 \\
360 \\
360\end{array}$ & $\begin{array}{l}470 \\
460 \\
475 \\
440 \\
470\end{array}$ & $\begin{array}{r}-15 \\
-20 \\
0 \\
-14 \\
-6\end{array}$ \\
\hline
\end{tabular}

* От выхода $\varepsilon$-капролактама прн пиролизе исходного ПҚА.

тельно (табл. 1). Хотя, следует отметить, выход пиролизной воды из образцов ПКА с добавкой ТФК существенно снижается, что может служить косвенным доказательством образования химической связи между модификатором и ПКА. Как видно из той же таблицы, добавка CM-5 не меняет состава продуктов пиролиза (различия носят лишь количественный характер), в том числе и количественный выход пиролизной воды, что связано в первую очередь с выделением большого количества воды при разложении чистого СM-5.

Дополнительно были определены выходы $\varepsilon$-капролактама при пиролизе модифицированных образцов ПКА и исходного полимера после их выдерживания в атмосфере различных газов - $\mathrm{CO}_{2}, \mathrm{H}_{2}, \mathrm{Ar}, \mathrm{NH}_{3} . \mathrm{Me}-$ тодом ступенчатой ПГХ определяли выход $\varepsilon$-капролактама при пиролизе исследуемых образцов, который также может служить критерием термической устойчивости полимера. С этой целью пиролизатор соединяли с испарителем хроматографа через обогревательное колено. Навеску образца (0,3 мг) нагревали в кварцевой трубке при $250-550^{\circ}$, ступенчато поднимая температуру через каждые $25^{\circ}$. Разделение и количественное определение $\varepsilon$-капролактама проводили на колонке из нержавеющей стали длиной 2 м и диаметром 4 мм с 
хроматон-N-супером. Температура колонки $-210^{\circ}$, скорость газаносителя (аргона) - 50 мл/мин, детектор - пламенно-ионизационный.

Полученные данные (табл. 2) свидетельствуют о том, что все исследованные модифицирующие добавки не оказывают влияния на термостабильность ПКА. Исключение составляет сажа ДГ-100, которая является активным стабилизатором термической деструкции ПКА (выход ع-капролактама при пиролизе заметно снижается и повышается температура его максимального выхода). Выдерживание ПКА в среде рабочих газов $\left(\mathrm{H}_{2}, \mathrm{CO}_{2}, \mathrm{Ar}, \mathrm{NH}_{3}\right)$ также не приводит к заметной деструкции полимера (табл. 2).

\section{Л И Т Е Р А Т У Р А}

1. Рейтлингер С. А. Проницаемость полимерных матерналов. М., 1974, 245.

2. Кириченко В., Кутьина Л., Гойхман А., Полуденная В., Демченко С., Киррет О., Когерман $A$. Модификация поликапроамида циклическими силазанами. Изв. АН ЭССР. Хим., 1982, 31, № 4, 299-300.

Киевский филиал ВНИНВпроекта

Институт химии

Поступила в редакцию $3 / \mathrm{X} 1984$

Академии наук Эстонской ССР 